\title{
Trends in the epidemiology of chronic obstructive pulmonary disease in England: a national study of 51804 patients
}

Colin R Simpson, Julia Hippisley-Cox and Aziz Sheikh

\section{ABSTRACT}

\section{Background}

Patients with chronic obstructive pulmonary disease (COPD) constitute a substantial burden to healthcare services. Analysis of national healthcare datasets offers the possibility to advance understanding about the changing epidemiology of COPD.

Aim

To investigate the epidemiology of physician-diagnosed COPD in general practice.

Design of study

Cross-sectional study.

Settings

A total of 422 general practices in England contributing to the QRESEARCH database.

\section{Method}

Data were extracted on 2.8 million patients, including age, sex, socioeconomic status, and geographical area. Trends over time for recorded physician diagnosis of COPD were analysed (2001-2005).

Results

There was little change over time in the incidence rate of COPD (2005: 2.0 per 1000 patient-years, 95\% confidence interval $[\mathrm{Cl}]=2.0$ to 2.1 , but a significant increase in lifetime prevalence rate (2001: 13.5 per 1000 patients [ $95 \% \mathrm{Cl}=13.4$ to 13.7$]$; $2005: 16.8[95 \% \mathrm{Cl}=$ 16.7 to 17.0$]$; $P<0.001$ ). In 2005, 51804 individuals or one in 59 people in England were recorded with physician-diagnosed COPD. The most deprived people (31.1 per 1000 patients; $95 \% \mathrm{Cl}=30.6$ to 31.7 ) and those living in the north east of England (29.2 per 1000 patients; $95 \% \mathrm{Cl}=28.4$ to 30.1 ) had the highest prevalence. The observed reduction in the rate of smoking by patients with COPD (overall decrease: $2.5 \%$; $P<0.001$ ) varied according to socioeconomic group (most affluent: $6.5 \%$ decrease, most deprived: $1.3 \%$ decrease).

\section{Conclusion}

Given the peak in the incidence rate of COPD, we may be approaching the summit of COPD incidence and prevalence in England. However, the number of people affected remains high and poses a major challenge for health services, particularly those in the north east of the country and in the most deprived communities in England. The very limited decrease in smoking rates among the more deprived groups of patients with COPD is also a cause for concern.

Keywords

chronic obstructive pulmonary disease; epidemiology; general practice; QRESEARCH; socioeconomic status.

\section{INTRODUCTION}

Chronic obstructive pulmonary disease (COPD) is now ranked by the World Health Organization as one of the most prevalent long-term conditions in the world. ${ }^{1}$ The global burden of COPD is predicted to rise, particularly in developing countries, because of the combination of ageing populations and increased smoking rates..$^{2,3}$ Although a steadily rising prevalence of physician-diagnosed COPD was found among women in the UK between 1990 and 1997, the prevalence among men reached a plateau. It was hypothesised that this sex disparity resulted from the rising prevalence of smoking among women in the 1980s and 1990s and the longstanding plateau in smoking cessation among men. ${ }^{4}$

The prevention of smoking and the promotion of smoking cessation services are the main strategies to prevent the occurrence and reduce the burden of COPD. In this vein, it is likely that the 2004 Public Service Agreement in England objectives of reducing overall adult smoking rates from $26 \%$ to $21 \%$ or less by $2010^{5}$ are likely to be surpassed. ${ }^{6}$ However, it is

CR Simpson, $P h D$, senior research fellow; $A$ Sheikh, $P h D$, professor of primary care R\&D, Allergy and Respiratory Research Group, Centre for Population Health Sciences, University of Edinburgh, Edinburgh. J Hippisley-Cox, MD, FRCP, professor of clinical epidemiology and general practice, Community Health Sciences, University of Nottingham, Nottingham.

\section{Address for correspondence}

Colin Simpson, Allergy and Respiratory Research Group, Centre for Population Health Sciences, University of Edinburgh, Medical School (Doorway 3), Teviot Place, Edinburgh, EH8 9AG. E-mail: c.simpson@ed.ac.uk

Submitted: 22 September 2009; Editor's response: 9 December 2009; final acceptance: 7 January 2010.

(C) British Journal of General Practice

This is the full-length article of an abridged version published in print. Cite this article as: Br J Gen Pract 2010; DOI: 10.3399/bjgp10X514729. 
unclear whether, in routine and manual workers, in whom smoking prevalence is considerably higher, the more ambitious targets to reduce prevalence will be achieved.

This study of national trends in the epidemiology of COPD was commissioned by the Chief Medical Officer for England because of growing concern about the high prevalence, disease burden, and healthcare costs (£800 million/€936 million annually) associated with COPD (and other respiratory disorders), and is being used to inform policy deliberations on respiratory service provision in England. ${ }^{7}$

\section{METHOD}

Version 10 of the QRESEARCH database was used for this analysis. This database contains representative anonymised aggregated health data derived from 422 general practices throughout England. Although these practices are self-selected, they are broadly representative of primary care practices in the UK. ${ }^{8}$ Data for this analysis were available for the period 1 January 2001 to 31 December 2005. Data were extracted for the period 1 January 2001 (2 885724 patients) to 31 December 2005 (2 968495 patients). The same practices were used throughout the study period. The methods used to collect primary care data for the QRESEARCH database have been previously described. ${ }^{9-12}$

In the UK, the majority of individuals resident (including children) are registered with primary care, which is free at the point of contact. Patients were included if they were registered on the first day of each year (for example, 1 January 2001) and were registered for the preceding 12 months. Those with incomplete data, that is, temporary residents, newly registered patients, and those who joined, left, or died during each study year were excluded. Patients were considered to have physician-diagnosed COPD if they had a relevant computer-recorded diagnostic Read Code (Box 1) in their electronic health record during the time period of interest.

Incidence rate was defined as the number of patients with a new case of physician-diagnosed COPD in a specific year, with the denominator being the number of patient-years of observation (calculated from the number of patients who were registered with practices for the entire year). Lifetime prevalence was defined as the proportion of people with COPD ever diagnosed by a physician, recorded (that is, on at least one occasion) in the GP records prior to the end of each study year (for example, before 31 December 2001); the denominator used to calculate the lifetime prevalence was the number of patients registered with the study practices at the

\section{How this fits in}

In England, there is growing concern that the disease burden and healthcare costs associated with chronic obstructive disease (COPD) will continue to rise.

This study found a large rise in the lifetime prevalence of physician-diagnosed COPD between 2001 and 2005, but a peak in the incidence rate. Although we

may be approaching the peak of the COPD incidence and prevalence in

England, the number of people affected remains high and poses a major

challenge for health services, particularly those in the north east of the country

and in the most deprived communities in England where high rates of COPD

exist. The very limited decrease in smoking rates among the more deprived

groups of patients with COPD is also a cause for concern.

end of each study year (for example, 31 December 2001). Smokers were defined as the proportion of patients with physician-diagnosed COPD and a smoking status code (Read Code: 137 and below) in the last 5 years recorded as a current smoker (in the year of study). Consultation rates (for any reason) per person per year were calculated. These included consultation with a GP or nurse in the home, at the surgery, and/or on the telephone.

Socioeconomic deprivation was defined on the basis of the Townsend score associated with the output area of the patient's postcode. The Townsend score is a composite score based on unemployment, overcrowding, lack of car, and non-owner occupancy. Higher scores indicate greater levels of socioeconomic deprivation. The cut-offs for the quintiles are based on the national distribution of Townsend scores derived from the 2001 Census.

\section{Statistical methods}

Because of known age and sex variations, rates of disease were standardised by sex and 5-year age bands. The mid-year population estimates for England in each year of study were used as the reference population and to estimate the actual number of people with COPD in England..$^{13}$ The $\chi^{2}$ test was used to compare categorical variables in different groups of patients. The Mantel-Haenszel $\chi^{2}$ test was used to investigate trends over time, this analysis was undertaken using Epilnfo2000 (World Health Organization, Geneva, Switzerland). Where appropriate, 95\% confidence intervals (Cls) are reported.

\section{RESULTS}

In 2001, 40545 patients had a physician diagnosis of COPD. In 2005, this had increased to 51804 patients.

\section{Trends in incidence rate}

Between 2001 and 2005, there was no significant change in the overall incidence rate of COPD in 


\section{Box 1. Chronic obstructive pulmonary disease Read Codes used in these analyses.}

\begin{tabular}{|c|c|}
\hline Read Code & Read term \\
\hline $\mathrm{H} 3 \ldots$ & Chronic obstructive pulmonary disease \\
\hline $\mathrm{H} 31 .$. & Chronic bronchitis \\
\hline H310 & Simple chronic bronchitis \\
\hline H3100 & Chronic catarrhal bronchitis \\
\hline $\mathrm{H} 310 \mathrm{z}$ & Simple chronic bronchitis NOS \\
\hline H311. & Mucopurulent chronic bronchitis \\
\hline $\mathrm{H} 3110$ & Purulent chronic bronchitis \\
\hline H3111 & Fetid chronic bronchitis \\
\hline H311z & Mucopurulent chronic bronchitis NOS \\
\hline H312. & Obstructive chronic bronchitis \\
\hline H3120 & Chronic asthmatic bronchitis \\
\hline H3210-1 & Chronic wheezy bronchitis \\
\hline H3121 & Emphysematous bronchitis \\
\hline H3122 & Acute exacerbation of chronic obstructive airways disease \\
\hline H3123 & Bronchiolitis obliterans \\
\hline $\mathrm{H} 312 \mathrm{z}$ & Obstructive chronic bronchitis NOS \\
\hline H313. & Mixed simple and mucopurulent chronic bronchitis \\
\hline H31y. & Other chronic bronchitis \\
\hline H31y1 & Chronic tracheobronchitis \\
\hline H31yz & Other chronic bronchitis NOS \\
\hline H31z. & Chronic bronchitis NOS \\
\hline H32.. & Emphysema \\
\hline H320. & Chronic bullous emphysema \\
\hline H3200 & Segmental bullous emphysema \\
\hline H3201 & Zonal bullous emphysema \\
\hline H3202 & Giant bullous emphysema \\
\hline H3203 & Bullous emphysema with collapse \\
\hline H3203-1 & Tension pneumatocoele \\
\hline H320z. & Chronic bullous emphysema NOS \\
\hline H321. & Panlobular emphysema \\
\hline H322. & Centrilobular emphysema \\
\hline H32y. & Other emphysema \\
\hline H32y0 & Acute vesicular emphysema \\
\hline H32y1 & Atrophic (senile) emphysema \\
\hline H32y2 & Acute interstitial emphysema \\
\hline H32yz & MacLeod's unilateral emphysema \\
\hline H32yz-1 & Other emphysema NOS \\
\hline H32z.. & Sawyer-Jones syndrome \\
\hline Н36.. & Emphysema NOS \\
\hline H37.. & Mild chronic obstructive pulmonary disease \\
\hline H38.. & Moderate chronic obstructive pulmonary disease \\
\hline НЗу.. & Severe chronic obstructive pulmonary disease \\
\hline H3y-1 & Other specified chronic obstructive airways disease \\
\hline Нзу0 & $\begin{array}{l}\text { Chronic obstructive pulmonary disease with acute lower } \\
\text { respiratory infection }\end{array}$ \\
\hline H3y1 & $\begin{array}{l}\text { Chronic obstructive pulmonary disease with acute } \\
\text { exacerbation, unspecified }\end{array}$ \\
\hline $\mathrm{H} 3 \mathrm{z}$. & Chronic obstructive airways disease NOS \\
\hline
\end{tabular}

NOS = not otherwise specified
England (2001: 2.0 per 1000 patient-years [95\% Cl = 1.9 to 2.0]; 2005: 2.0 per 1000 patient-years [95\% Cl $=2.0$ to 2.1]). Sex-specific incidence rates are detailed in Figure 1 and Table 1. It is of note that a relatively large increase in incidence rate of physician-diagnosed COPD for men and women took place in 2004 before returning to near 2001 levels by the end of the study period.

\section{Trends in lifetime prevalence}

Overall, the recorded lifetime prevalence of COPD increased from 13.5 per 1000 patients $(95 \% \mathrm{Cl}=$ 13.4 to 13.7$)$ in 2001 to 16.8 per 1000 patients $(95 \%$ $\mathrm{Cl}=16.7$ to 17.0$)$ in 2005 : a $3.3 \%$ rise $(P<0.001)$. The recorded lifetime prevalence by sex can be seen in Figure 1 and Table 2; these data demonstrate significant increases over time in males and females $(P<0.001)$.

\section{Geographical and socioeconomic variations in prevalence}

There were large differences in the prevalence of COPD between regions within England. For example, the highest age-standardised prevalence of COPD was observed in the north east of the country, which was over twice that observed in the south east (Table 3). There were also substantial socioeconomic differences found, with the most socioeconomically deprived having three times the COPD prevalence rate of the most affluent patients (Table 4).

\section{National estimate of numbers of patients with COPD}

It was estimated that $842100(95 \% \mathrm{Cl}=834800$ to 849400 ) of 50 million people in England were diagnosed with COPD in 2005; this translates into approximately one person in 59 receiving a diagnosis of COPD at some point in their lives. In the most socioeconomically deprived quintile, one in 32 patients were diagnosed with COPD, compared with one in 98 patients in the most affluent quintile.

\section{Consultation rates}

In 2005, patients with COPD had the highest yearly rate of GP and nurse consultations when compared with other groups of patients with respiratory diseases (after standardising for age and regardless of the reason for the encounter; Table 5.

\section{Smoking trends}

Between 2001 and 2005, the overall prevalence of smoking among patients with COPD decreased from $39.2 \%(95 \% \mathrm{Cl}=37.1$ to 48.3$)$ to $36.7 \%(95 \% \mathrm{Cl}=$ 33.6 to 42.4$)$, a $2.5 \%$ reduction $(P<0.001)$. In 2005 , the highest prevalence of smoking was found among women with COPD aged $45-50$ years of age who 


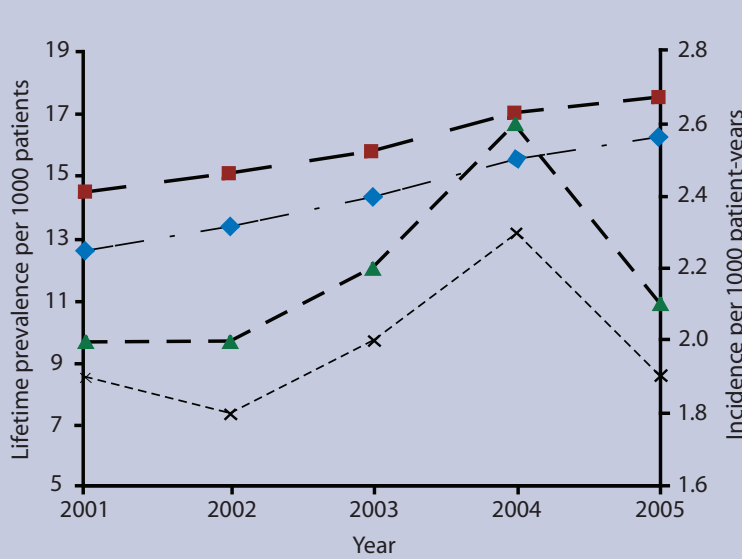

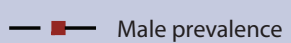

$\longrightarrow$ - Female prevalence

- $\ldots$ - Male incidence

$---\boldsymbol{x - - -}$ Female incidence
Figure 1.

Physician-diagnosed chronic obstructive pulmonary disease. were in the most deprived quintile $(72.3 \%$ [95\% Cl = 62.7 to 81.9$]$ ). During the study period, among the most deprived group of patients with COPD, there was a much smaller decrease in the proportion smoking when compared with the most affluent group (Table 6).

\section{DISCUSSION}

\section{Summary of main findings}

This study, using routinely collected electronic data from one of the world's largest national primary care datasets, has confirmed that physician-diagnosed COPD is common and results in considerable use of

Table 1. Incidence rate of chronic obstructive pulmonary disease (COPD).

\begin{tabular}{cccccc} 
Year & Total patients & $\begin{array}{c}\text { Patients } \\
\text { with COPD }\end{array}$ & $\begin{array}{c}\text { Crude rate per } \\
\text { 1000 patient-years }\end{array}$ & $\begin{array}{c}\text { Age-sex-standardised rate } \\
\text { rate per } 1000 \\
\text { patient-years (95\% Cl) }\end{array}$ & $\begin{array}{c}\text { Relative \% change } \\
\text { in standardised } \\
\text { rate (from 2001) }\end{array}$ \\
\hline $\begin{array}{l}\text { Females } \\
2001\end{array}$ & 1444314 & 2904 & 2.0 & $1.9(1.9$ to 2.0$)$ & N/A \\
2002 & 1454521 & 2707 & 1.9 & $1.8(1.7$ to 1.9$)$ & -0.1 \\
2003 & 1467867 & 3014 & 2.1 & $2.0(1.9$ to 2.1$)$ & 0.1 \\
2004 & 1466942 & 3549 & 2.4 & $2.3(2.3$ to 2.4$)$ & 0.4 \\
2005 & 1485738 & 2981 & 2.0 & $1.9(1.9$ to 2.0$)$ & 0.0 \\
\hline Males & & & & & N/A \\
2001 & 1441410 & 3033 & 2.1 & $2.0(2.0$ to 2.1$)$ & 0.0 \\
2002 & 1451814 & 3020 & 2.1 & $2.0(1.9$ to 2.1$)$ & 0.2 \\
2003 & 1464853 & 3245 & 2.2 & $2.2(2.1$ to 2.2$)$ & 0.6 \\
2004 & 1463393 & 3900 & 2.7 & $2.6(2.5$ to 2.7$)$ & 0.1 \\
2005 & 1482757 & 3302 & 2.2 & $2.1(2.1$ to 2.2$)$ & \\
\hline
\end{tabular}

$N / A=$ not applicable.

Table 2. Lifetime prevalence rate of chronic obstructive pulmonary disease (COPD).

\begin{tabular}{|c|c|c|c|c|c|}
\hline Year & Total patients & $\begin{array}{c}\text { Patients } \\
\text { with COPD }\end{array}$ & $\begin{array}{l}\text { Crude rate per } \\
1000 \text { patients }\end{array}$ & $\begin{array}{l}\text { Age-sex standardised rate } \\
\text { per } 1000 \text { patients }(95 \% \mathrm{Cl})\end{array}$ & $\begin{array}{c}\text { Change in standardised } \\
\text { rate (from 2001) }\end{array}$ \\
\hline \multicolumn{6}{|c|}{ Females } \\
\hline 2001 & 1444314 & 19025 & 13.2 & 12.6 (12.5 to 12.8$)$ & N/A \\
\hline 2002 & 1454521 & 20343 & 14.0 & 13.4 (13.2 to 13.6$)$ & 0.8 \\
\hline 2003 & 1467867 & 21797 & 14.9 & 14.3 (14.1 to 14.5$)$ & 1.7 \\
\hline 2004 & 1466942 & 23618 & 16.1 & 15.5 (15.3 to 15.7$)$ & 2.9 \\
\hline 2005 & 1485738 & 24889 & 16.8 & $16.2(16.0$ to 16.4$)$ & 3.6 \\
\hline \multicolumn{6}{|l|}{ Males } \\
\hline 2001 & 1441410 & 21520 & 15.2 & 14.5 (14.3 to 14.7$)$ & N/A \\
\hline 2002 & 1451814 & 22666 & 15.8 & 15.1 (14.9 to 15.3$)$ & 0.6 \\
\hline 2003 & 1464853 & 23901 & 16.5 & 15.8 (15.6 to 16.0$)$ & 1.3 \\
\hline 2004 & 1463393 & 25643 & 17.6 & 17.0 (16.8 to 17.2$)$ & 2.5 \\
\hline 2005 & 1482757 & 26915 & 18.3 & 17.5 (17.3 to 17.7$)$ & 3.0 \\
\hline
\end{tabular}

$N / A=$ not applicable 


\begin{tabular}{|c|c|c|c|c|c|}
\hline $\begin{array}{l}\text { Government } \\
\text { Office region }\end{array}$ & Total patients & $\begin{array}{c}\text { Patients } \\
\text { with COPD }\end{array}$ & $\begin{array}{l}\text { Crude rate per } \\
1000 \text { patients }\end{array}$ & $\begin{array}{c}\text { Age-sex standardised } \\
1000 \text { patients } \\
(95 \% \mathrm{Cl})\end{array}$ & $\begin{array}{c}\text { Change in standardised } \\
\text { rate (from 2001) }\end{array}$ \\
\hline \multicolumn{6}{|l|}{2001} \\
\hline North East & 156875 & 3469 & 22.1 & 22.2 (21.5 to 22.9 ) & N/A \\
\hline North West & 255253 & 5323 & 20.9 & 21.1 (20.6 to 21.7$)$ & $\mathrm{N} / \mathrm{A}$ \\
\hline $\begin{array}{c}\text { Yorkshire and } \\
\text { Humberside }\end{array}$ & 326791 & 6337 & 19.4 & 18.1 (17.7 to 18.6$)$ & N/A \\
\hline South West & 389147 & 5172 & 13.3 & $12.8(12.5$ to 13.2$)$ & N/A \\
\hline West Midlands & 222635 & 3256 & 14.6 & $12.5(12.0$ to 12.9$)$ & N/A \\
\hline East Midlands & 421898 & 4981 & 11.8 & 11.3 (11.0 to 11.6$)$ & N/A \\
\hline East of England & 269505 & 3062 & 11.4 & $11.1(10.7$ to 11.5$)$ & $\mathrm{N} / \mathrm{A}$ \\
\hline London & 344755 & 3993 & 11.6 & $11.8(11.4$ to 12.1$)$ & N/A \\
\hline South East & 478086 & 4952 & 10.4 & $10.3(10.0$ to 10.6$)$ & N/A \\
\hline \multicolumn{6}{|l|}{2005} \\
\hline North East & 164875 & 4687 & 28.4 & 29.2 (28.3 to 30.1$)$ & 7.0 \\
\hline North West & 267032 & 6384 & 23.9 & 24.5 (23.9 to 25.1$)$ & 3.4 \\
\hline \multicolumn{6}{|l|}{ Yorkshire and } \\
\hline Humberside & 342439 & 7626 & 22.3 & 20.1 (20.4 to 21.3 ) & 2.0 \\
\hline South West & 402309 & 6643 & 16.5 & $15.9(15.6$ to 16.3$)$ & 3.1 \\
\hline West Midlands & 228175 & 4274 & 18.7 & $15.8(15.3$ to 16.3$)$ & 3.3 \\
\hline East Midlands & 427556 & 6842 & 16.0 & $15.4(15.0$ to 15.7$)$ & 4.1 \\
\hline East of England & 275496 & 4044 & 14.7 & 14.3 (13.9 to 14.8$)$ & 3.2 \\
\hline London & 360513 & 4804 & 13.3 & 14.1 (13.7 to 14.5$)$ & 2.3 \\
\hline South East & 489971 & 6500 & 13.3 & 13.1 (12.8 to 13.4$)$ & 2.8 \\
\hline
\end{tabular}

$N / A=$ not applicable.

\begin{tabular}{|c|c|c|c|c|c|}
\hline $\begin{array}{l}\text { Year and } \\
\text { Townsend quintile }\end{array}$ & Total patients & $\begin{array}{l}\text { Patients } \\
\text { with COPD }\end{array}$ & Crude \% & $\begin{array}{c}\text { Age-sex-standardised } \\
\%(95 \% \mathrm{Cl})\end{array}$ & $\begin{array}{c}\text { Change in standardised } \\
\text { rate (from 2001) }\end{array}$ \\
\hline \multicolumn{6}{|l|}{2001} \\
\hline 1 (most affluent) & 634434 & 5828 & 9.2 & 8.3 (8.1 to 8.5$)$ & $\mathrm{N} / \mathrm{A}$ \\
\hline 2 & 565812 & 6141 & 10.9 & 9.8 (9.5 to 10.0$)$ & N/A \\
\hline 3 & 536218 & 7232 & 13.5 & 12.4 (12.1 to 12.7$)$ & N/A \\
\hline 4 & 497925 & 8588 & 17.3 & 17.2 (16.9 to 17.6$)$ & N/A \\
\hline 5 (most deprived) & 535216 & 11705 & 21.9 & 24.8 (24.4 to 25.3$)$ & $\mathrm{N} / \mathrm{A}$ \\
\hline \multicolumn{6}{|l|}{2005} \\
\hline 1 (most affluent) & 648634 & 7861 & 12.1 & $10.2(10.0$ to 10.5$)$ & 1.9 \\
\hline 2 & 580431 & 8084 & 13.9 & 12.1 (11.8 to 12.4$)$ & 2.3 \\
\hline 3 & 552702 & 9664 & 17.5 & $16.2(15.8$ to 16.5$)$ & 3.8 \\
\hline 4 & 515271 & 10784 & 20.9 & 22.0 (21.6 to 22.5$)$ & 4.8 \\
\hline 5 (most deprived) & 567835 & 14219 & 25.0 & 31.1 (30.6 to 31.7 ) & 6.3 \\
\hline
\end{tabular}

healthcare services in general practice. The study data reveal very considerable regional and socioeconomic inequalities in the diagnosed prevalence of COPD, which have become more pronounced over the study period. Encouragingly, there was a significant reduction in smoking prevalence among these patients, although this was more marked among affluent patients than among those who were more socioeconomically deprived.

\section{Strengths and limitations of the study}

The main strengths of this study include the interrogation of patient-level computerised data from an extremely large nationally representative dataset, and the fact that all contributing practices used the same computing systems for electronically recording clinical data. The study design employed ensured that there was no risk of selection bias due to nonresponders or recall bias.

There are a number of limitations related to the use of large routinely collected data from primary care, including the dependence on clinician-recorded diagnosis of COPD (especially as the reliability of diagnosis and recording could not be checked; for 
Table 5. Consultation rates with GPs and nurses for any reason by patients' respiratory conditions in 2005.

\begin{tabular}{|c|c|c|c|c|}
\hline Disease & Total consultations & Disease patients & Crude rate per person & $\begin{array}{l}\text { Age-sex-standardised } \\
\text { rate per person }(95 \% \mathrm{Cl})\end{array}$ \\
\hline $\begin{array}{l}\text { Chronic obstructive } \\
\text { pulmonary disease }\end{array}$ & 571922 & 51804 & 11.0 & 7.9 (7.8 to 8.0$)$ \\
\hline Asthma & 2012681 & 333294 & 6.0 & 6.4 (6.4 to 6.5$)$ \\
\hline Cystic fibrosis & 4033 & 706 & 5.7 & 5.1 (4.9 to 5.4 ) \\
\hline $\begin{array}{l}\text { Lower respiratory } \\
\text { tract infection }\end{array}$ & 3797841 & 566643 & 6.7 & 6.1 (6.1 to 6.2 ) \\
\hline Lung cancer & 23824 & 1846 & 12.9 & 7.9 (7.5 to 8.2$)$ \\
\hline Mesothelioma & 941 & 69 & 13.6 & 4.1 (3.6 to 4.6 ) \\
\hline Occupational lung disease & 27441 & 3345 & 8.2 & 6.7 (6.5 to 6.9$)$ \\
\hline Pneumonia & 311762 & 44069 & 7.1 & 6.1 (6.1 to 6.1$)$ \\
\hline Tuberculosis & 99045 & 13762 & 7.2 & 5.2 (5.1 to 5.2$)$ \\
\hline $\begin{array}{l}\text { Upper respiratory } \\
\text { tract infection }\end{array}$ & 6099503 & 1162796 & 5.3 & 5.5 (5.5 to 5.5$)$ \\
\hline All patients & 12749498 & 2958366 & 4.3 & 4.3 (4.3 to 4.3$)$ \\
\hline
\end{tabular}

\section{Table 6. Proportion of patients with chronic obstructive pulmonary disease (COPD)} recorded as smokers.

\begin{tabular}{|c|c|c|c|c|c|}
\hline $\begin{array}{l}\text { Year and Townsend } \\
\text { quintile }\end{array}$ & $\begin{array}{l}\text { Total COPD } \\
\text { patients }^{\mathrm{a}}\end{array}$ & Smokers & Crude \% & $\begin{array}{c}\text { Age-sex-standardised } \\
\%(95 \% \mathrm{Cl})\end{array}$ & $\begin{array}{c}\text { Change in standardised } \\
\text { rate (from 2001) }\end{array}$ \\
\hline \multicolumn{6}{|l|}{2001} \\
\hline 1 (most affluent) & 5233 & 1427 & 27.3 & 29.9 (23.7 to 43.3$)$ & N/A \\
\hline 2 & 5527 & 1648 & 29.8 & 31.6 (24.5 to 45.3$)$ & N/A \\
\hline 3 & 6476 & 2190 & 33.8 & 35.9 (30.6 to 48.2$)$ & N/A \\
\hline 4 & 7724 & 2986 & 38.7 & 38.0 (33.9 to 48.7$)$ & N/A \\
\hline 5 (most deprived) & 10680 & 4971 & 46.5 & 46.6 (43.1 to 50.6$)$ & N/A \\
\hline \multicolumn{6}{|l|}{2005} \\
\hline 1 (most affluent) & 7763 & 1770 & 22.8 & 23.4 (19.6 to 33.6$)$ & -6.5 \\
\hline 2 & 7993 & 1986 & 24.9 & 27.5 (24.0 to 38.1$)$ & -4.1 \\
\hline 3 & 9550 & 2760 & 28.9 & 31.8 (28.3 to 38.2$)$ & -4.1 \\
\hline 4 & 10680 & 3743 & 35.1 & 37.2 (32.9 to 44.1$)$ & -0.8 \\
\hline 5 (most deprived) & 14078 & 5969 & 42.4 & 45.3 (39.2 to 57.1$)$ & -1.3 \\
\hline
\end{tabular}

${ }^{a}$ With smoking status recorded. N/A = not applicable.

example, spirometry data were not available to confirm or refute clinical diagnoses) and possible improvements in recording over the study time period, which may not reflect the true incidence or prevalence of disease in the community.

There may also be an underestimate in relation to the actual population prevalence of COPD, especially in individuals with mild disease who may not have consulted a primary care physician. As there is a considerable delay between changes in the causative factors of COPD and its presentation, the relatively short time window over which trends were studied is another limitation, and therefore it is possible that changes in incidence and prevalence between one year and the next are more likely to reflect changes in health service use and changes in physician recognition of the disease (rather than changes in true prevalence). In particular, the introduction of the new General Medical Services contract to UK primary care in April 2004, ${ }^{14}$ which introduced incentives to create and maintain a registry of patients with COPD, may be a cause of the increase in case ascertainment found in the penultimate year of the study.

It is also possible that the introduction of the new contract caused some diagnostic drift from patients labelled as having asthma to COPD, and that the contract requirement for a more systematic reliable diagnosis of COPD, confirmed by spirometry and reversibility testing for new patients (introduced in 2005), and all patients (introduced in 2006), may have further impacted the incidence and prevalence of physician-diagnosed COPD after this study period. However, despite the possibility of confusion with other airways disorders, ${ }^{15}$ a good correspondence has been found between clinician and electronic 
patient diagnoses of COPD and differentiation between asthma. ${ }^{16}$

\section{Comparison with existing literature}

The incidence rate of 2.0 per 1000 patient-years was similar to that found among young European adults (2.8 per 1000 patient-years), ${ }^{17}$ but higher than the annual average incidence found among adults in Bergen, Norway $\left(0.7 \%\right.$ annual incidence).$^{18}$ It is likely that this lower incidence is due to the use of different disease criteria rather than differences in environmental exposure. Lifetime prevalence in the present study $(1.7 \%)$ was less than that found using a questionnaire survey of patients (aged $\geq 30$ years) from two primary care practices in Manchester, England (4.1\%), ${ }^{19}$ and less than the prevalence found using Dutch general practice data (5.5\%), ${ }^{20}$ and also estimates from the Health Survey for England 2001 (women 2.4\%; men 3.9\%), ${ }^{21}$ but similar to prevalence estimates reported by the Quality and Outcomes Framework (1.5\%). ${ }^{22}$ Prevalence rates at the beginning of the study period in 2001 (female: 1.3\%; male $1.5 \%$ ) were also very similar to those found in 1997 using the UK General Practice Research Database (female 1.4\%; male 1.6\%). ${ }^{4}$

Higher rates of COPD diagnosed in primary care in northern England and deprived communities found in the present study have also been previously reported. ${ }^{23}$ Mean consultation rates (7.9 per year) were higher than those from a survey conducted in 2002 of 500 patients throughout the UK with COPD (6.6 visits per year), although this was a telephone survey that relied on patient recollection and may have been affected by recall bias. ${ }^{24}$

\section{Implications for future research and clinical practice}

Given the peak in the incidence rate of COPD and the substantial decreases in prevalence of smoking in the overall population, ${ }^{5}$ it is likely that we are approaching the peak of COPD incidence and prevalence in England. Rather than any increases in causative factors that may have occurred in previous decades, increases in the prevalence of physician-diagnosed COPD recorded by general practice during the study period, and the increase of COPD incidence in 2004, are likely to represent not only the continuing impact of increasing survival among patients, ${ }^{16}$ but also the increased clinician awareness of COPD. This is largely due to the imminent introduction of a new incentive-based quality-improvement contract in April $2004,{ }^{14}$ which led to improvements being made in identifying and recording individuals with the disease. The higher rate of consultations found here is a reflection of the high use of primary healthcare services by patients with COPD.
Given these issues, healthcare planners need to consider that patients with COPD are greater users of healthcare services, with more individuals being diagnosed by physicians with COPD, and that continuing efforts are required to diagnose this disease early so that effective management can be provided..$^{25}$ It is also apparent that additional burden is placed on services in the north east of England and the most deprived communities where, for those with the disease, there have been only very modest declines in the rates of smoking. This is a cause for concern and poses a challenge for health services, as it is recognised that COPD may still progress in individuals even if they quit smoking. With the imminent publication of the Clinical Strategy for COPD, ${ }^{26}$ it is clear that there is a need for the continued provision of resources for promotion of smoking cessation, monitoring, pulmonary rehabilitation, and management of patients with COPD, particularly for those in the north east of the country and in the most deprived communities in England.

\section{Funding body}

Colin R Simpson is supported by a Health Services and Health of the Public postdoctoral fellowship from the Chief Scientist Office of the Scottish Government (PDF/08/02).

\section{Ethical approval}

All data analyses were conducted using de-identified data and were subject to the QRESEARCH research governance processes.

\section{Competing interests}

Julia Hippisley-Cox is Director of QRESEARCH (a not-forprofit organisation owned by the University of Nottingham and EMIS, commercial supplier of computer systems for $60 \%$ of GP practices in the UK). Colin R Simpson and Aziz Sheikh have no competing interests.

\section{Acknowledgements}

We would like to record our thanks to the contributing EMIS practices and patients, and to EMIS for providing technical expertise in creating and maintaining QRESEARCH. We thank QRESEARCH staff for their contribution to data extraction, analysis, and presentation. These findings have been reported in Primary care epidemiology of allergic disorders: analysis using QRESEARCH database 2001-2006, which is published by the NHS Health and Social Care Information Centre.

\section{Discuss this article}

Contribute and read comments about this article on the Discussion Forum: http://www.rcgp.org.uk/bjgp-discuss

\section{REFERENCES}

1. World Health Organization. World Health Report: life in the 21st century: a vision for all. Geneva: World Health Organization, 1998.

2. Niu S, Yang G, Chen Z, et al. Emerging tobacco hazards in china: 2. early mortality results from a prospective study. BMJ 1998; 317(7170): 1423-1424.

3. Calverley PMA. Caring for the burden of COPD. Thorax 2006; 61(10): 831-832.

4. Soriano JB, Maier WC, Egger P, et al. Recent trends in physician diagnosed COPD in women and men in the UK. Thorax 2000; 55(9): 789-794.

5. Her Majesty's Treasury. 2004 spending review public service agreements 2005-8. London: Her Majesty's Treasury, 2004.

6. Simpson CR, Hippisley-Cox J, Sheikh A. Trends in the epidemiology of smoking in the United Kingdom. Br J Gen Pract 
2010; 10.3399/bjgp10X483544.

7. The Chief Medical Officer. On the state of the public health: annual report of the Chief Medical Officer. London: The Department of Health, 2005.

8. Hippisley-Cox J, Vinogradova Y, Coupland C, Pringle M. Comparison of key practice characteristics between general practices in England and Wales and general practices in the QRESEARCH data. http://www.qresearch.org/Public_Documents/Characteristics\%20o $\% 20$ QRESEARCH\%20practices\%20_database\%20version\%208_\% 20v1.0.pdf (accessed 1 Jun 2010).

9. Sheikh A, Hippisley-Cox J, Newton J, Fenty J. Trends in national incidence, lifetime prevalence and adrenaline prescribing for anaphylaxis in England. J R Soc Med 2008; 101(3): 139-143.

10. Ghouri N, Hippisley-Cox J, Newton J, Sheikh A. Trends in the epidemiology and prescribing of medication for allergic rhinitis in England. J R Soc Med 2008; 101(9): 466-472.

11. Simpson CR, Newton J, Hippisley-Cox J, Sheikh A. Incidence and prevalence of multiple allergic disorders recorded in a national primary care database. J R Soc Med 2008; 101(11): 558-563.

12. Simpson CR, Newton J, Hippisley-Cox J, Sheikh A. Trends in the epidemiology and prescribing of medication for eczema in England. J R Soc Med 2009; 102(3): 108-117.

13. Office for National Statistics. The 2001 census. http://www.ons.gov.uk/census/index.html (accessed 18 Jan 2010).

14. The NHS Confederation. Investing in general practice: the new General Medical Services contract. London: British Medical Association.

http://www.bma.org.uk/employmentandcontracts/independent_co ntractors/general_medical_services_contract/investinggp.jsp (accessed 18 Jan 2010).

15. Wolfenden H, Bailey L, Murphy K, Partridge MR. Use of an open access spirometry service by general practitioners. Prim Care Respir J 2006; 15(4): 252-255.

16. Soriano JB, Vestbo J, Pride NB, et al. Survival in COPD patients after regular use of fluticasone propionate and salmeterol in general practice. Eur Respir J 2002; 20(4): 819-825.

17. De Marco R, Accordini S, Cerveri I, et al. Incidence of chronic obstructive pulmonary disease in a cohort of young adults according to the presence of chronic cough and phlegm. Am J Respir Crit Care Med 2007; 175(1): 32-39.

18. Johannessen A, Omenaas E, Bakke P, Gribbin J. Incidence of GOLD-defined chronic obstructive pulmonary disease in a general adult population. Int J Tuberc Lung Dis 2005; 9(80): 926-932.

19. Frank TL, Hazell ML, Linehan MF, et al. The estimated prevalence of chronic obstructive pulmonary disease in a general practice population. Prim Care Respir J 2007; 16(3): 169-173.

20. Bischoff EWMA, Schermer TRJ, Bor H, et al. Trends in the COPD prevalence and exacerbation rates in Dutch primary care. Br J Gen Pract 2009; 59: 927-933.

21. Nacul LC, Soljak M, Meade T. Model for estimating the population prevalence of chronic obstructive pulmonary disease: cros sectional data from the Health Survey for England. Popul Health Metr 2007; 5: 8

22. The Prescribing Support Unit. Quality and Outcome Framework disease prevalence for April 2007 to March 2008, England. Leeds: The Health and Social Care Information Centre, 2008.

23. Smith CJP, Gribben J, Challen KB, Hubbard RB. The impact of the 2004 NICE guideline and 2003 General Medical Services contract on COPD in primary care in the UK. Q J Med 2008; 101(2): $145-153$.

24. Britton M. The burden of COPD in the UK. Results from the confronting COPD survey. Resp Med 2003; 97: S71-S79.

25. Jones R. Can early diagnosis and effective management combat the irresistible rise of COPD. Br I Gen Pract 2006; 56(530): 652-654.

26. The British Lung Foundation. National clinical strategy for COPD. London: The British Lung Foundation.

http://www.lunguk.org/media-and-

campaigning/campaigns/what_is_the_national_strategy_for_copd. htm (accessed 18 Jan 2010). 